\section{Combining IPC with static compression treatment, to improve patient's compliance using innovative smart materials}

\section{Omer Zelka}

CEO and founder of ElastiMed Ltd., Yokneam Ilit, Israel

Medical compression stocking with a medium to high levels of compression suffers from limited patient's compliance mainly due to difficulties in doffing and donning and due to patient's discomfort. ${ }^{1}$ IPC limits patient's mobility, and suffers from a noisy activation and high cost. ${ }^{2} \mathrm{New}$ development in the field of smart materials, enables combining the clinical benefits of both static compression and IPC without their disadvantages, thus improving patient's compliance. ElastiMed is using an electroactive material that expands when activated by an electric pulse. Using that material, ElastiMed have created a batteryoperated, that applies active compression, similar to IPC, with a constant nominal pressure, similar to a medical compression stocking (Figure 1).

The device is initially worn by the patient, using 4 parallel Velcro straps, which go in opposite directions. A mechanical mechanism within each strap, verifies that the strap is applied with $30( \pm 3) \mathrm{mmHg}$ initial pressure. The patient then presses the ON button, which causes the straps to expand, releasing the initial pressure in all 4 straps, lowering it by $10 \mathrm{mmHg}$, and keeping a constant static pressure of $20( \pm 3)$ $\mathrm{mmHg}$.

Then, the straps start contracting sequentially, by raising the pressure by 10 $\mathrm{mmHg}$, starting from the ankle and up the calf, and then releasing the pressure back to $20 \mathrm{mmHg}$. To terminate the treatment, the patient presses again on the $\mathrm{ON}$ button to turn the device off, and then removes the Velcro straps. Treatment duration could be determined by the Physician, and can be used in a hospital or home environment.

The battery is rechargeable by a micro USB and is good for 20-25 hours of work time. The device is silent, and does not generate any heat.

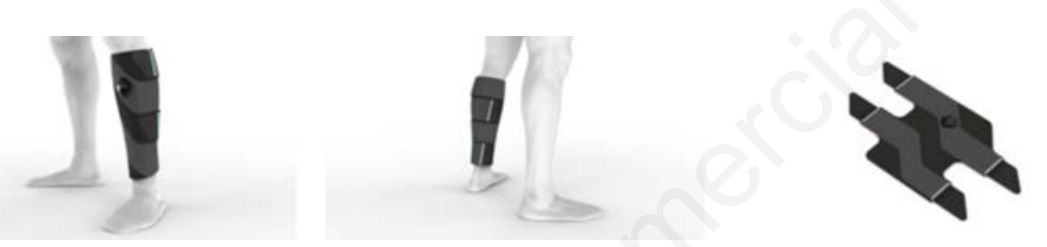

Figure 1. ElastiMed's smart compression device.

Correspondence: Omer Zelka, CEO and founder of ElastiMed, HaKidma 7, Yokneam Ilit, Israel.

E-mail: omer@elastimed.com

Conference presentation: International Compression Club (ICC) Meeting, Rotterdam, 2018.

This work is licensed under a Creative Commons Attribution 4.0 License (by-nc 4.0).

(c) Copyright O. Zelka, 2018

Licensee PAGEPress, Italy

Veins and Lymphatics 2018; 7:7982

doi:10.4081/vl.2018.7982

Results from an initial clinical study, showing measurements of peak flow velocity in the Popliteal vein on healthy patients using the device, which is scheduled for the beginning of January, will be presented in the presentation.

\section{References}

1. Raju S, Hollis K, Neglen P. Use of compression stockings in chronic venous disease: patient compliance and efficacy. Ann Vasc Surg 2007;21:790-5.

2. Ivascu FA, Garcia GD. Diagnosis and treatment of deep venous thrombosis: drugs and filters. in current therapy of trauma and surgical critical care. Mosby Elsevier; 2008. pp 718-720. 